\title{
Substitution of Rare Earth Elements in Hot Rolled Magnesium Alloys with Improved Mechanical Properties
}

\author{
Kristina Neh ${ }^{1, a^{*}}$, Madlen Ullmann ${ }^{1, b}$, Rudolf Kawalla ${ }^{1, c}$ \\ ${ }^{1}$ Institute of Metal Forming, Technische Universität Bergakademie Freiberg, Germany \\ aKristina.Neh@imf.tu-freiberg.de, bMadlen.Ullmann@imf.tu-freiberg.de, \\ 'Rudolf.Kawalla@imf.tu-freiberg.de
}

Keywords: New magnesium alloys, hot rolling, offset-method, mechanical properties

\begin{abstract}
Magnesium alloys containing rare earth elements offer excellent strength at room temperature as well as at elevated temperatures and are distinguished by a high ignition-resistance. However, with regard to cost efficiency and the conservation of resources, these alloys are not suitable for commercial industrial applications. Therefore, the research project SubSEEMag (Substitution of rare earth elements in magnesium alloys) coordinated by the Institute of Metal Forming/Technische Universität Bergakademie Freiberg focusses on the development of alternative alloy compositions, which meet the requirements on materials properties of magnesium alloys for industrial applications and production costs. Several magnesium alloys containing zinc, aluminum, manganese and calcium were poured in cylindrical molds at the Helmholtz-Zentrum Geesthacht. The characterization of the as-cast condition was carried out by light and scanning electron microscopy. Phase compositions were determined using EDX analysis. The $\mathrm{Mg}$ alloys were homogenized at different temperatures for evaluating optimal setting for parameters of heat treatment. Afterwards, hot rolling to a final thickness of $2.7 \mathrm{~mm}$ was conducted. The influence of temperature and time of the annealing on the microstructure and the mechanical properties of the hot rolled sheets have been investigated. The results were discussed in comparison to commercially available Mg-RE alloys.
\end{abstract}

\section{Introduction}

Magnesium alloys, especially magnesium-rare earth systems (Mg-RE), offer attractive properties for applications in the aerospace and automotive industries. For structural parts the development of magnesium wrought alloys with high strength, good corrosion resistance and enhanced formability is required. Currently, commercial magnesium alloys containing rare earth elements are predominantly available as cast alloys, e. g. EZ33, ZE41 or WE54 [1-3]. The ASTM standard of USA includes only one magnesium wrought alloy (ZE10). The above alloys are characterized by good strength properties at room temperature as well as at elevated temperatures, sufficient weldability and high creep resistance. Besides the commercially available alloying systems alternative compositions, exemplarily mentioned $\mathrm{Mg}-\mathrm{Y}-\mathrm{Nd}$ [4] or $\mathrm{Mg}$-Gd-(Y) [5-7], were developed. The increased strength properties of magnesium alloys with RE addition are mainly attributed to two major strengthening mechanisms: precipitation hardening and solid solution strengthening. Compared to other alloying elements, e. g. aluminum or zinc, the effect of solid solution strengthening by gadolinium or yttrium is much higher. It is suggested, that size and/or modulus misfits between the solute and solvent atoms are responsible for these enhanced effect [5]. Furthermore, age-hardening leads to the precipitation of strengthening phases, which results in increasing hardness values and in an excellent creep resistance due to the high thermal stability of the precipitations $[8,9]$. Besides the advantages of $\mathrm{Mg}-\mathrm{RE}$ alloys the high costs for rare earth metals as well as potential hazards of toxic residuals, which arise during the mining of the metals, have to be considered. With regard to cost efficiency and the conservation of resources, these alloys are not suitable for commercial industrial applications. Consequently, intensive efforts of substituting rare earth metals by other alloying elements increase. Aluminum, calcium, manganese and zinc seem to be potential candidates for developing alternative magnesium alloys, which offer a comparable 
performance to Mg-RE alloys. The mentioned alloying elements are attributed with an improvement of corrosion ( $\mathrm{Zn}, \mathrm{Mn})$ and creep resistance (Ca, Mn) as well as with the ability of enhancing strength properties by precipitation hardening ( $\mathrm{Zn}, \mathrm{Ca}$ ) and/or solid solution strengthening (Al) $[1,10,11]$.

Potential alloy compositions are assumed to be the ZA (Mg-Zn-Al), ZAX (Mg-Zn-Al-Ca), and the MX (Mg-Mn-Ca) system. Zhang et al. (2008) [12] investigated the influence of calcium addition to an $\mathrm{Mg}-1.8 \mathrm{Zn}-1.1 \mathrm{Mn}$ alloy on occurring precipitations, regarding type and volume fracture, as well as the grain size. Increasing $\mathrm{Ca}$ amount leads to a significant grain refinement from $175 \mu \mathrm{m}(0.3 \mathrm{wt} \%)$ to $63 \mu \mathrm{m}(0.5 \mathrm{wt} \%)$. Ca addition of $0.5 \mathrm{wt} \%$ ensures best mechanical properties in as-cast condition with ultimate tensile strength (UTS) of $180 \mathrm{MPa}, 90 \mathrm{MPa}$ yield strength (YS) and an elongation at fracture of $9 \%$ [12]. Magnesium alloys of the ZAX system were focused in the studies of Rudi (2000) [13], Mo (2014) [14] and Homayun (2014) [15]. Simultaneous addition of zinc and aluminum results in an appreciable improvement of the mechanical properties. However, a strong dependence attributed to the aluminum content is apparent (Fig. 1). At a constant zinc amount of $4 \mathrm{wt} \%$ the addition of $1 \mathrm{wt} \%$ to $3 \mathrm{wt} \% \mathrm{Al}$ results in an increase of the UTS by $25 \%$ due to solid solution strengthening and grain refinement (average grain size decreases from $116 \mu \mathrm{m}$ without aluminum to $76 \mu \mathrm{m}$ at $7.5 \mathrm{wt} \% \mathrm{Al}$ ). Aluminum contents up to $5 \mathrm{wt} \%$ cause deterioration of the elongation at fracture. It is suggested that higher fraction of $\mathrm{Mg}_{17} \mathrm{Al}_{12}$ phase and its networked arrangement along the grain boundaries lead to decreasing elongation values [15].

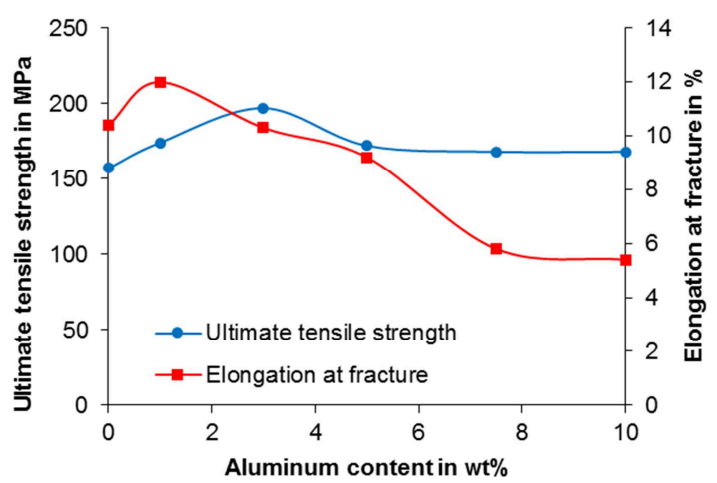

Fig. 1. Mechanical properties of the ZAX alloys in as-cast condition depending on the aluminum content (at a constant zinc amount of $4 \mathrm{wt} \%$ ) [15]

In this work, the potential of several magnesium alloys containing $\mathrm{Al}, \mathrm{Ca}, \mathrm{Zn}$ and/or $\mathrm{Mn}$ in different compositions for the substitution of $\mathrm{Mg}-\mathrm{RE}$ alloys is investigated. After casting, the magnesium alloys were homogenized and hot rolled to sheets with a final thickness of $2.7 \mathrm{~mm}$. Microstructure of several conditions was characterized using optical and scanning electron microscopy. Phase compositions were analyzed by EDX and XRD analysis. For the determination of the mechanical properties tensile tests were conducted.

\section{Materials and Experimental Procedure}

Feedstock. Three magnesium alloys, containing aluminum, zinc, manganese and/or calcium, were used: ZA21, ZAX210, and MX21. Bolts of these alloys with $125 \mathrm{~mm}$ diameter were produced via casting at the Helmholz-Zentrum Geesthacht. Spark emission spectrometry was applied in order to determine the chemical composition, listed in Table 1.

Table 1. Chemical composition of the used magnesium alloys determined via spark emission spectrometry at Helmholtz-Zentrum Geesthacht, Balance: $\mathrm{Mg}$ (in wt $\%$ )

\begin{tabular}{|c|c|c|c|c|c|c|c|c|c|}
\hline Alloy & $\mathrm{Al}$ & $\mathrm{Mn}$ & $\mathrm{Zn}$ & $\mathrm{Ca}$ & $\mathrm{Cu}$ & $\mathrm{Fe}$ & $\mathrm{Ni}$ & $\mathrm{Si}$ & Others \\
\hline \hline ZA21 & 0.985 & 0.014 & 1.94 & $<0.001$ & $<0.001$ & 0.011 & $<0.001$ & $<0.001$ & $<0.04$ \\
\hline ZAX210 & 0.955 & 0.015 & 1.82 & 0.113 & 0.001 & 0.011 & $<0.001$ & $<0.001$ & $<0.04$ \\
\hline MX21 & 0.022 & 1.83 & 0.002 & 0.323 & $<0.002$ & $<0.01$ & $<0.002$ & $<0.001$ & $<0.04$ \\
\hline
\end{tabular}


Experimental Procedure. The as-cast condition is unfavorable as initial state for forming due to the occurrence of brittle secondary phases as well as a coarse microstructure. To improve the forming behavior of the investigated Mg-alloys a heat treatment for homogenization of the microstructure is required. Different temperatures from $340{ }^{\circ} \mathrm{C}$ to $420{ }^{\circ} \mathrm{C}$ with holding times between $4 \mathrm{~h}$ and $12 \mathrm{~h}$ were applied to establish optimal parameters. For the following investigations thin slices were cut from the bolts. Hot rolling was conducted using a reversing mill in laboratory scale (Fig. 2). Reductions between $20 \%$ and $25 \%$ per pass (in total 6 passes) were chosen to produce sheets with a final thickness of $2.7 \mathrm{~mm}$. After the $3^{\text {rd }}$ pass an intermediate heat treatment was required to restore the initial rolling temperature as well as to soften the microstructure as a result of recrystallization. Subsequently, a final annealing of the rolled sheets was carried out. The analysis of the microstructure was accomplished by using light microscopy. Mechanical properties were determined by tensile testing.

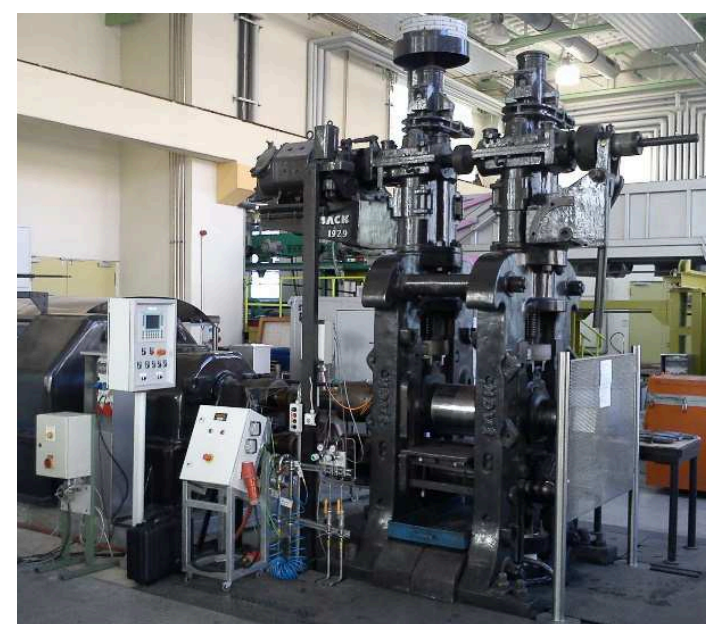

\begin{tabular}{|c|c|}
\hline \multicolumn{2}{|c|}{ Parameters of hot rolling: } \\
\hline Initial thickness & $8.5 \mathrm{~mm}$ \\
\hline Final thickness & $2.7 \mathrm{~mm}$ \\
\hline Rolling speed & $0.5 \mathrm{~m} / \mathrm{s}$ \\
\hline Roll temperature & $130^{\circ} \mathrm{C}$ \\
\hline Rolling temperature & $400^{\circ} \mathrm{C}$ \\
\hline Passes & 6 \\
\hline Reduction per pass & $20 \% \ldots 25 \%$ \\
\hline Intermediate heat treatment & after $3^{\text {rd }}$ pass \\
\hline
\end{tabular}

Fig. 2. Reversing mill in laboratory scale and parameters of hot rolling

\section{Results and Discussion}

Characterization of the Initial State: Optical (Fig. 3) and scanning electron microscopy (Fig. 4) were carried out in order to characterize the microstructure of the investigated magnesium alloys in the as-cast condition (Fig. 2). Both zinc and aluminum containing Mg alloys (Fig. $4 \mathrm{a}$ and b) offer a dendritic $\alpha-\mathrm{Mg}$ matrix. Intermetallic compounds are predominantly located in the interdendritic areas. Addition of $\mathrm{Ca}$ results in significant refinement of the dendrites and consequently in a more homogenous distribution of intermetallic phases. Based on the chemical composition determined by EDX and XRD analysis the occurring phases in the ZA21 alloy are assigned being $\operatorname{Mg}_{17}(\mathrm{Al}, \mathrm{Zn})_{12}$ ( $\gamma$-phase) and $\mathrm{Al}_{5} \mathrm{Mg}_{11} \mathrm{Zn}_{4}$ ( $\phi$-phase) (Fig. 5a). In ZAX210 phase composition cannot be classified clearly. The coarse microstructure impedes the assignment of individual phases. More precise classification of the phase composition requires further investigations. Chemical composition of magnesium matrix, which is impoverished of alloying elements, was determined being $98 \mathrm{wt} \% \mathrm{Mg}$ and $2 \mathrm{wt} \% \mathrm{Zn}$ (dark grey, Fig. 4b). Some areas are enriched with $\mathrm{Zn}$ and Al (light grey, Fig. 4b) and consist of $95 \mathrm{wt} \% \mathrm{Mg}, 4 \mathrm{wt} \% \mathrm{Zn}$ and $1 \mathrm{wt} \% \mathrm{Al}$. Interdendritic phases reveal a chemical composition of $54 \mathrm{wt} \% \mathrm{Mg}, 31 \mathrm{wt} \% \mathrm{Zn}, 9 \mathrm{wt} \% \mathrm{Ca}$ and $6 \mathrm{wt} \%$ Al. The microstructure of the MX21 (Fig. 3c) alloy comprises fine grains of the $\alpha$-magnesium with secondary phase precipitation arranged along the grain boundaries. According to the chemical composition and confirmed by $\mathrm{x}-$ ray investigations the occurring phases are $\mathrm{Mg}_{2} \mathrm{Ca}$ (Fig. 5b). 

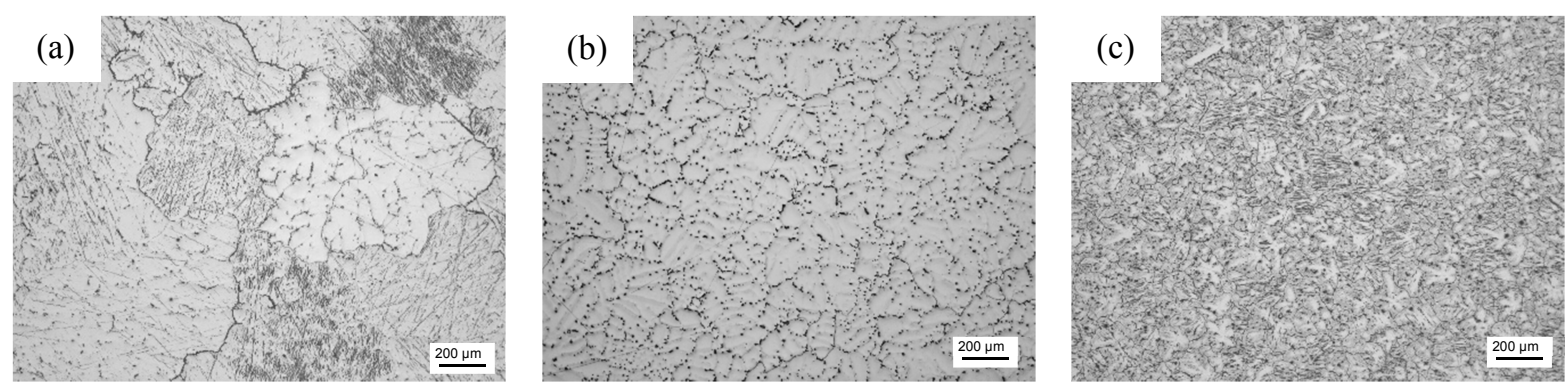

Fig. 3. Optical micrographs of the investigated magnesium alloys in as-cast condition: (a) ZA21, (b) ZAX210 and (c) MX21
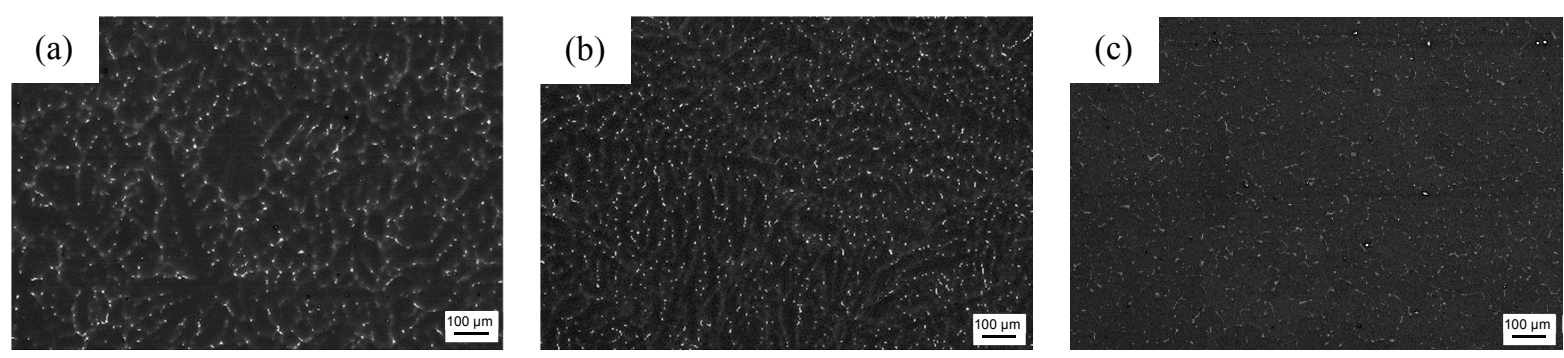

Fig. 4. SEM micrograph of the investigated magnesium alloys in as-cast condition: (a) ZA21, (b) ZAX210 and (c) MX21

Homogenization. In the ZA21 and ZAX210 alloy (Fig. 6a and b), the homogenization leads to the transformation of the dendritic structure (as-cast condition) into a grain structure. Ca addition results in the formation of finer grains due to its grain refining effect. Average cord length of the grains is $500 \mu \mathrm{m}$ in ZA21 and $85 \mu \mathrm{m}$ in ZAX210. The grain refinement can be attributed to the grain growth restriction, which is induced by calcium aggregations at the grain boundaries $[16,17]$. The heat treatment promotes the dissolution of the solutes into the matrix effectuating the decomposition of the intermetallic compounds. The homogenized MX21 (Fig. 6c) alloy offers a grain structure with an average cord length of about $97 \mu \mathrm{m}$. An influence of the homogenization on the precipitations cannot be established.

Hot Rolling. After homogenization the investigated magnesium alloys were hot rolled in 6 passes with an intermediate heat treatment subsequent to the $3^{\text {rd }}$ rolling pass. Fig. 7 shows the microstructure of ZA21, ZAX210 and MX21 in rolled condition (after the $3^{\text {rd }}$ pass). Total deformation degree achieved $\varphi=0.53$. 
(a)

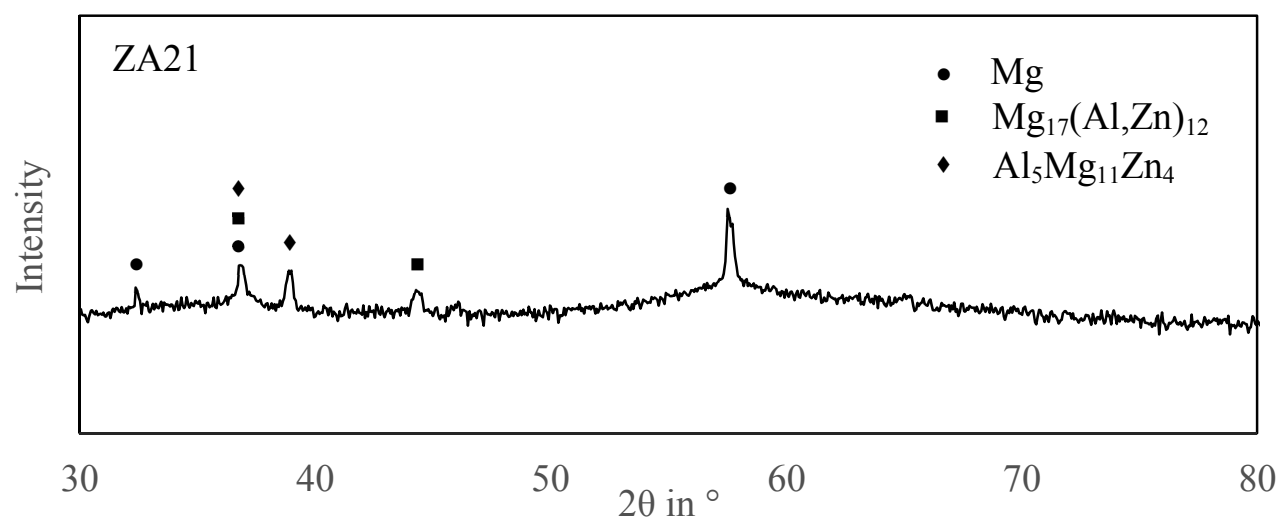

(b)

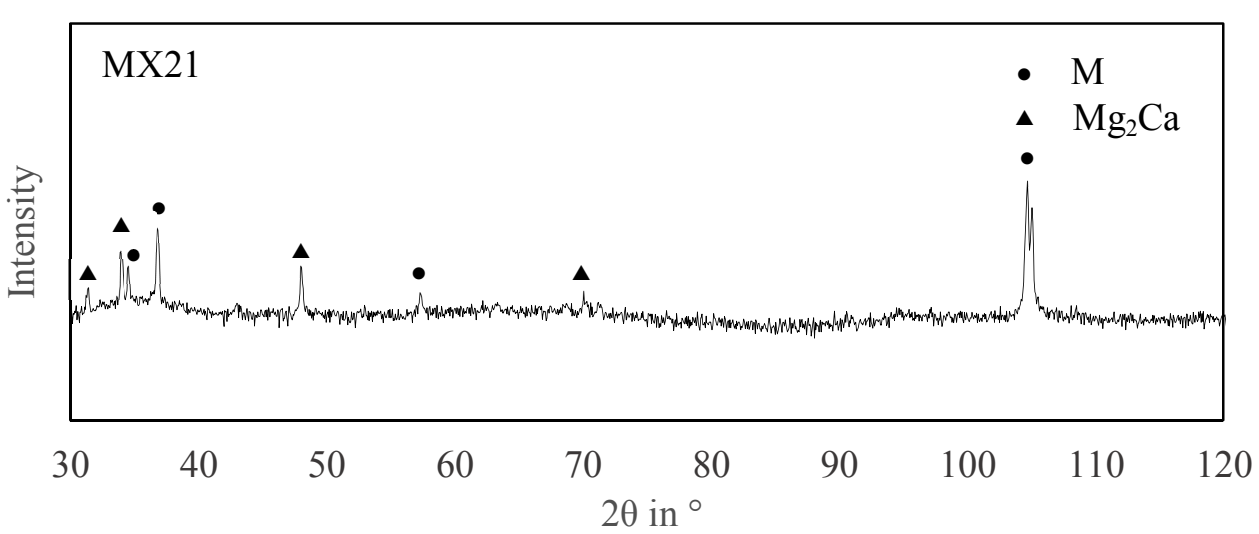

Fig. 5. XRD analysis of as-cast condition (a) ZA21 and (b) MX21
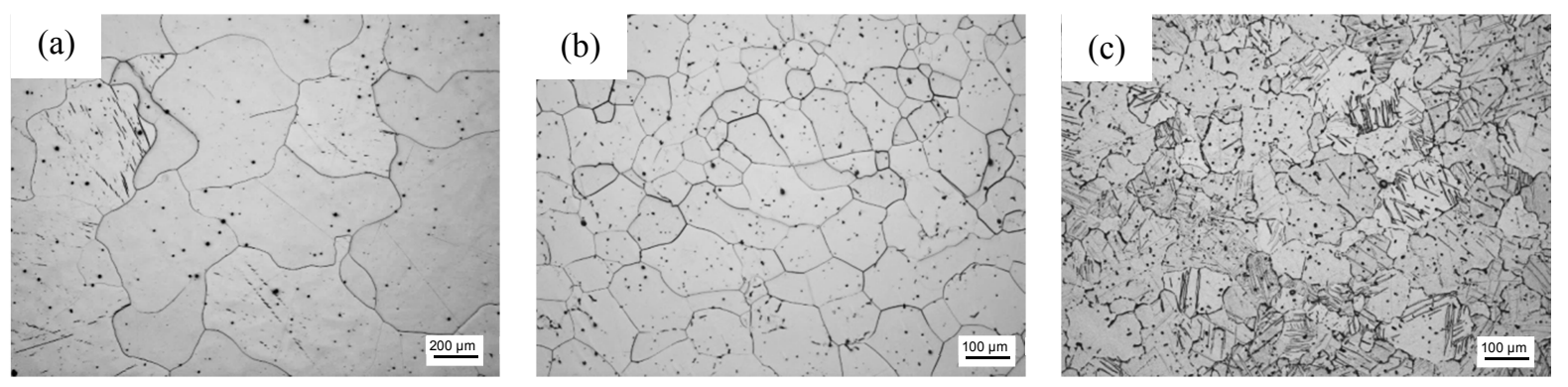

Fig. 6. Microstructure after homogenization: (a) ZA21, 380C, $8 \mathrm{~h}$, (b) ZAX210, $420{ }^{\circ} \mathrm{C}, 8 \mathrm{~h}$ and (c) $\mathrm{MX} 21,420^{\circ} \mathrm{C}, 8 \mathrm{~h}$

The structural constitution of the hot rolled magnesium alloys depends strongly on the chemical composition. ZA21 offers occasionally occurring large grains surrounded by finer recrystallized microstructure. The addition of a small amount of calcium (ZAX210) leads to the formation of an entirely different structure. Twinning is apparent in the coarse microstructure of the ZAX210 alloy. Recrystallization cannot be evidenced. The grains of the MX21 alloy are elongated in rolling direction resulting in the alignment of the intermetallic compounds, which are mainly located along the grain boundaries. In single grains twinning occurs. With the exception of ZA21, which offers a partially recrystallized microstructure, further work hardening may cause material failure. In order to continue hot rolling without crack initiation, an intermediate heat treatment is required. 

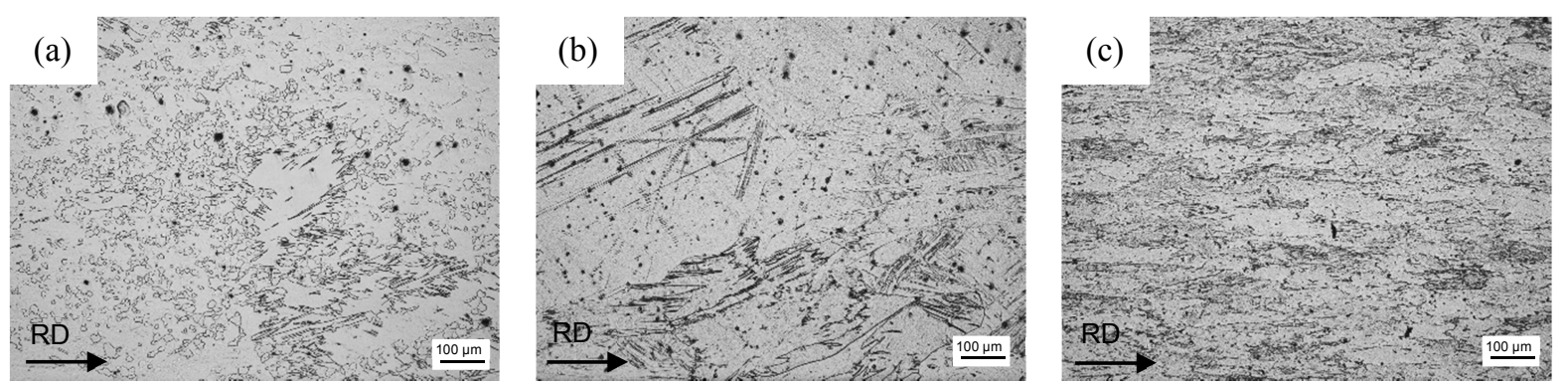

Fig. 7. Microstructure in rolled condition after the $3^{\text {rd }}$ rolling pass: (a) ZA21, (b) ZAX210 and (c) MX21

Intermediate heat treatment was carried out at different temperatures $\left(300{ }^{\circ} \mathrm{C}, 350{ }^{\circ} \mathrm{C}\right.$, and $400{ }^{\circ} \mathrm{C}$ ) and a holding time of $2 \mathrm{~h}$. Microstructures of the annealed magnesium alloys are shown in Fig. 8. ZA21 and ZAX210 offer microstructures with equiaxed grains. Higher annealing temperatures lead to increasing grain size. In ZAX210 $\left(300{ }^{\circ} \mathrm{C}: 7.9 \mu \mathrm{m} \rightarrow 400{ }^{\circ} \mathrm{C}: 23.5 \mu \mathrm{m}\right)$ this effect is not as strong as in ZA21 $\left(300^{\circ} \mathrm{C}: 24.6 \mu \mathrm{m} \rightarrow 82.0 \mu \mathrm{m}\right)$ due to the calcium addition. MX21 shows only a small increase in the average cord length of the grains from $8.1 \mu \mathrm{m}\left(300{ }^{\circ} \mathrm{C}\right)$ to $12.9 \mu \mathrm{m}\left(400^{\circ} \mathrm{C}\right)$. It is suggested that thermally stable precipitations impede grain growth. A temperature of $350{ }^{\circ} \mathrm{C}$ was considered to be appropriate for the intermediate heat treatment in order to achieve a good workability for continuing hot rolling.
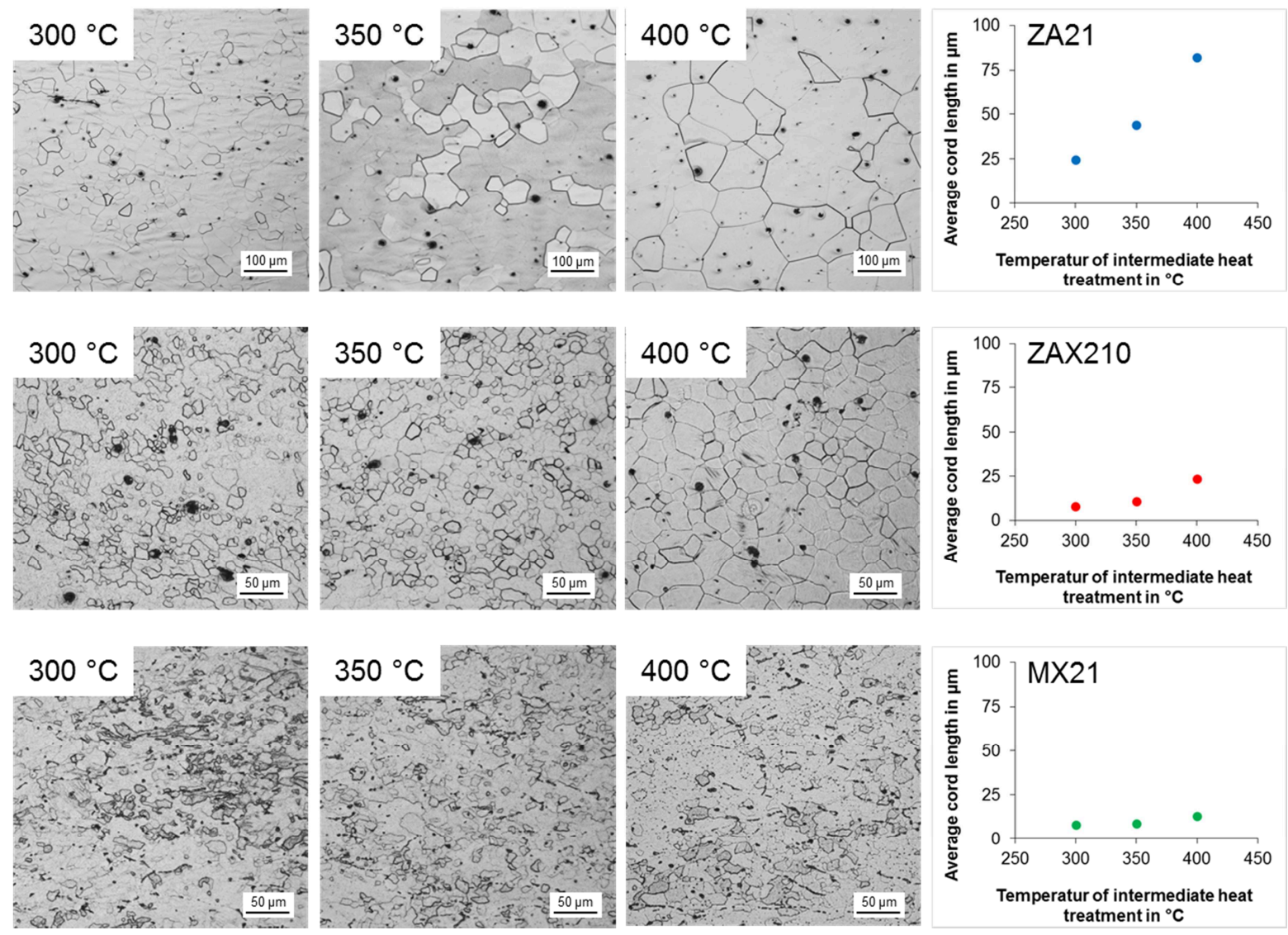

Fig. 8. Microstructural and grain size evolution of ZA21, ZAX210 and MX21 during intermediate heat treatment at different temperatures ranging from $300{ }^{\circ} \mathrm{C}$ to $400{ }^{\circ} \mathrm{C}$, holding time was $2 \mathrm{~h}$

After finish-rolling to a final thickness of $2.7 \mathrm{~mm}$ the microstructures of the investigated magnesium alloys offer grains, which are elongated in rolling direction. In addition, twinning can be observed. In ZA21 dynamic recrystallization leads to the formation of small grains, that enclose areas of deformed microstructure. In order to achieve a homogeneous microstructure with equiaxed grains, a final heat treatment at $330{ }^{\circ} \mathrm{C}$ and a duration of 45 min was carried out. Fig. 9 illustrates 
the microstructure of ZA21, ZAX210 and MX21 after final annealing. All alloys reveal a complete recrystallized microstructure. Grain size varies from $7.1 \mu \mathrm{m}$ for MX21 to $34.1 \mu \mathrm{m}$ for ZA21. Calcium addition (ZAX210) results in grain refinement apparent from lower average cord length of $11.0 \mu \mathrm{m}$.
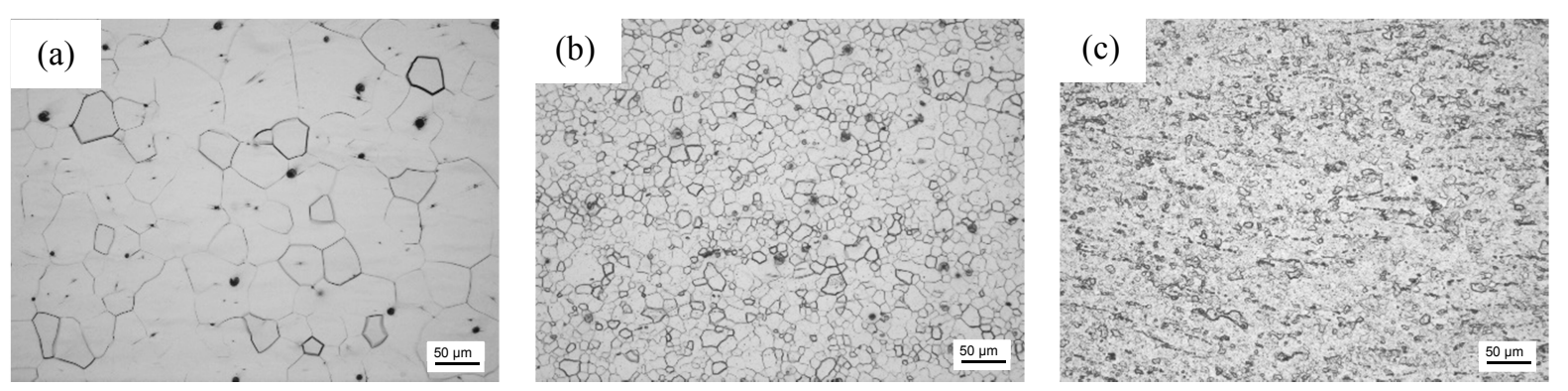

Fig. 9. Microstructure after final annealing $\left(330^{\circ} \mathrm{C}, 45 \mathrm{~min}\right)$ : (a) ZA21, (b) ZAX210 and (c) MX21

The mechanical properties of the hot rolled and annealed sheets were determined by tensile testing at room temperature. For the classification, the yield strength, ultimate tensile strength and elongation at fracture of new developed magnesium alloys renouncing the usage of rare earth elements were compared to two magnesium alloys with rare earth elements (data from the literature): (1) the only standardized Mg-RE-wrought alloy ZE10 [1] and (2) WE43, containing a large amount of RE [18]. Fig. 10 shows the comparison of the different magnesium alloys. It can be held up positively that the investigated magnesium alloys surpass the mechanical properties of ZE10. Especially MX21 offers significantly higher yield strength and elongation at fracture. Unfortunately, the high strength values of WE43 cannot be attained by the RE-free magnesium alloys yet. Advancement of the rolling schedule and optimization of the process parameters are required in order obtain further improvement of the mechanical properties.

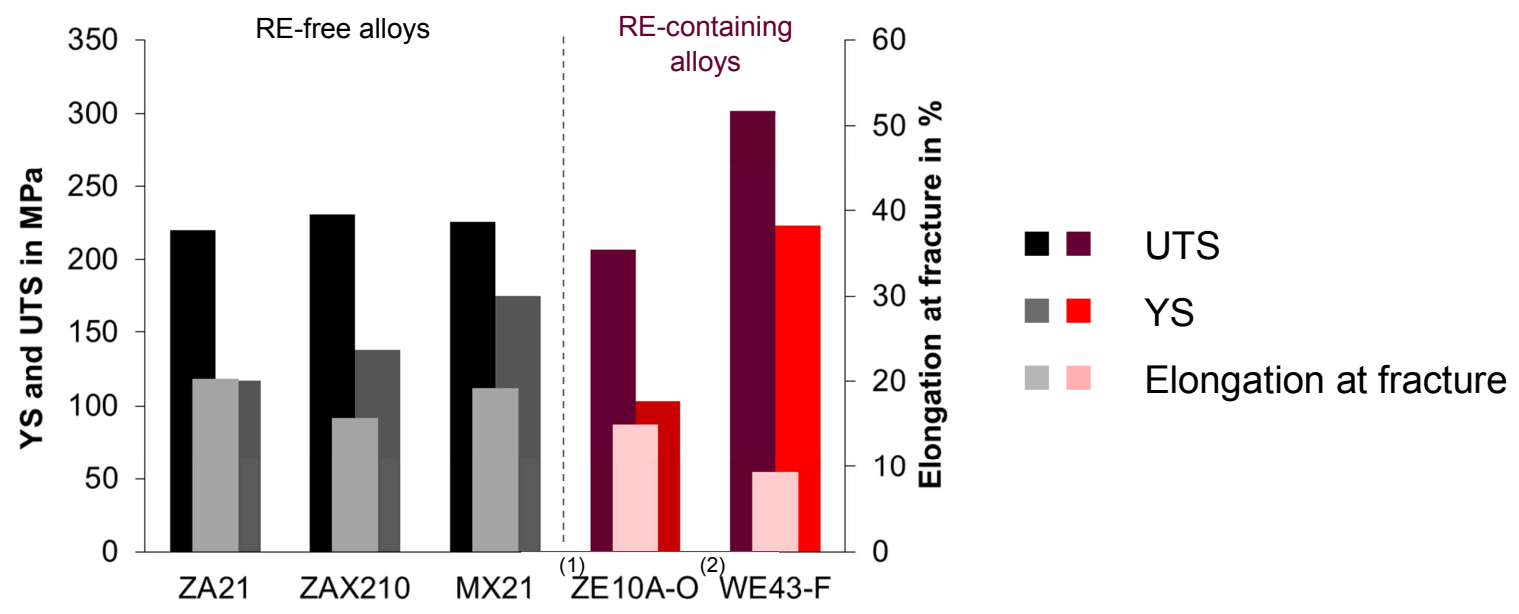

Fig. 10. Mechanical properties of ZA21, ZAX210 and MX21 in hot rolled and final annealed condition compared to magnesium alloys containing rare earth elements $[1,18]$

\section{Conclusions}

Aim of the present study was the investigation of several magnesium alloys containing $\mathrm{Al}, \mathrm{Ca}, \mathrm{Zn}$ and/or $\mathrm{Mn}$ in different compositions and evaluation of their potential for the substitution of Mg-RE alloys. In this regard, it is important to generate new magnesium wrought alloys with suitable mechanical properties. For the investigated magnesium alloys ZA21, ZAX210 and MX21 a rolling and heat treatment schedule was developed in order to produce sheets with a final thickness of $2.7 \mathrm{~mm}$ successfully. In the as-rolled and annealed condition the sheets offer good mechanical properties, exceeding those of ZE10. Especially MX21 offers significantly higher yield strength and elongation at fracture. It is desirable to advance the rolling schedule and optimize the process parameters in order obtain further improvement of the mechanical properties. Moreover, 
investigations to examine other materials properties (high-temperature strength and corrosion resistance), which are characteristic for $\mathrm{Mg}-\mathrm{RE}$ alloys, are required to classify the new magnesium alloys compared to the existing spectrum of magnesium wrought alloy.

\section{Acknowledgement}

This study arises within the research project SubSEEMag. The authors thank the Federal Ministry of Education and Research for the financial support.

\section{References}

[1] L.L. Rokhlin: Magnesium Alloys Containing Rare Earth Metals. Taylor \& Francis, London, 2003

[2] T. Ryspaev, Z. Trojanova, O. Padalka, V. Wesling: Microstructure of superplastic QE22 and EZ33 magnesium alloys. Mater. Lett. 62 (2008) 4041-4043

[3] M. Bobby Kannan, W. Dietzel, C. Blawert, A. Atrens, P. Lyon: Stress corrosion cracking of rare-earth containing magnesium alloys ZE41, QE22 and Elektron 21 (EV31A) compared with AZ80

[4] P.J. Apps, H. Karimzadeh, J.F. King, G.W. Lorimer: Phase compositions in magnesium-rare earth alloys containing yttrium, gadolinium or dysprosium. Scripta Mater. 48 (2003) 475-481

[5] L. Gao, R.S. Chen, E.H. Han: Effects of rare-earth elements Gd and Y on the solid solution strengthening of Mg alloys. J. Alloy Compd. 481 (2009) 379-384

[6] T. Honma, T. Ohkubo, S. Kamado, K. Hono: Effect of $\mathrm{Zn}$ additions on the age-hardening of Mg-2.0Gd-1.2Y-0.2Zr alloys. Acta Mater. 55 (2007) 4137-4150

[7] J. Wang, J. Meng, D. Zhang, D. Tang: Effect of Y for enhanced age hardening response and mechanical properties of Mg-Gd-Y-Zr alloys. Mat. Sci. Eng. A 456 (2007) 78-84

[8] X. Gao, S.M. He, X.Q. Zeng, L.M. Peng, W.J. Ding, J.F. Nie: Microstructure evolution in a Mg-15Gd-0.5Zr (wt\%) alloy during isothermal aging at $250{ }^{\circ} \mathrm{C}$. Mat. Sci. Eng. A 431 (2006) 322327

[9] N. Balasubramani, U.T.S. Pillai, B.C. Pai: Effect of Zn concentration on the microstructure and phase formation of Mg-5Gd alloy. J. Alloy Compd. 460 (2008) L6-L10

[10] C. Kammer: Magnesium Taschenbuch. Aluminium-Verlag, Düsseldorf, 2000

[11] R.W. Cahn, P. Haasen, E.J. Kramer: Materials Science and Technology - Volume 8: Structure and Properties of Nonferrous Alloys. VCH Verlagsgesellschaft mbH, Weinheim, 1996

[12] E. Zhang, L. Yang: Microstructure, mechanical properties and bio-corrosion properties of Mg-Zn-Mn-Ca alloy for biomedical application. Mat. Sci. Eng. A 497 (2008) 111-118

[13] R.S. Rudi, S. Kamado, N. Ikeya, T. Araki, Y. Kojima: High Temperature Strength of Semisolid Formed Mg-Zn-Al-Ca Alloys. Mater. Sci. Forum 350-351 (2000) 79-86

[14] W. Mo, L. Zhang, G. Wu, Y. Zhang, W. Liu, C. Wang: Effects of processing parameters on microstructure and mechanical properties of squeeze-cast Mg-12Zn-4Al-0.5Ca alloy. Mater. Design 63 (2014) 729-737

[15] B. Homayun, A. Afshar: Microstructure, mechanical properties, corrosion behavior and cytotoxicity of Mg-Zn-Al-Ca alloys as biodegradable materials. J. Alloy Compd. 607 (2014) 1-10

[16] P. Li, B. Tang, E.G. Kandalova: Microstructure and properties of AZ91D alloy with Ca additions. Mater. Lett. 59 (2005) 671-675

[17] Y.C. Lee, A.K. Dahle, D.H. StJohn: The Role of Solute in Grain Refinement of Magnesium. Metall. Mater. Trans. A 31 (2000) 2895-2906

[18] K. Cho, T. Sano, K. Doherty, C. Yen, G. Gazonas, J. Montgomery, P. Moy, B. Davis, R. DeLorme: Magnesium Technology and Manufacturing for Ultra Lightweight Armored Ground Vehicles. Reprint form the Proceedings of the 2008 Army Science Conference, Orlando, FL, 3 December 2008 